\title{
Türkiye'de Sigortacılığın Son Yıllardaki Gelişim Eğiliminin Değerlendirilmesi: 2016-2019 Yılları Arası Dönem İçin Sigortacılık Sektörüne Yönelik Bir Etkinlik Analizi
}

\author{
Selim Duramaz ${ }^{a}$
}

Özet

Türkiye'de sigortacıllk sektöründe farklı sigorta branşlarına yönelik sigorta bilinci her geçen gün artmakta, bununla eşdeğer olarak sektörde üretilen poliçe sayısı da günden güne artmaktadır. Bu kapsamda nitelik olarak artan sigorta göstergelerinin nicelik açısından da değerlendirilmesi, sektöre yönelik bir performans tablosunun ortaya çıkarılması amaçlarından hareketle çalışmada 2016-2019 yılları arasında seçilen bazı göstergeler üzerinden sigortacılık sektöründe toplam prim üretimine göre pazar payı sıralamasında üst sırada yer alan ilk 14 şirkete yönelik bir etkinlik analizi gerçekleştirilmiştir. Analiz yöntemi olarak veri zarflama analizi kullanılmıştır. Çalışmanın sonucunda, incelenen yıllarda toplam prim üretimine göre üst sıralarda yer alan firmaların genel olarak etkinlik düzeyleri de iyi seviyelerde seyretmekle beraber, bazı yıllarda bu durumun tersi süreçler de yaşandığı analiz sonuçlarından gözlenmiştir. Buna göre şirketler istihdam sayıları ve poliçe adetlerini daha verimli kullanarak karlılıklarını ve prim üretimlerini arttırma yoluna gitmelidirler.
Anahtar Kelimeler

Etkinlik

Türk Sigortacilık Sektörü

Veri Zarflama Analizi.

Makale Hakkında

Geliş Tarihi: 28.08.2021

Kabul Tarihi: 15.12.2021

Doi: $10.18026 /$ cbayarsos.988137

\section{Evaluation of the Development Trend of Insurance in Turkey in Recent Years: An Efficiency Analysis for the Insurance Sector for the Period Between 2016-2019}

\begin{abstract}
Insurance awareness for different insurance branches in the insurance sector in Turkey is increasing day by day, and the number of policies produced in the sector is increasing day by day. In this context, with the aim of evaluating the insurance indicators that increase in quality in terms of quantity and revealing a performance table for the sector, in the study, a list of the top 14 companies in the market share ranking according to the total premium production in the insurance sector, based on some indicators selected between 2016-2019 activity analysis was carried out. Data envelopment analysis was used as the analysis method. As a result of the study, it has been observed from the analysis results that although the efficiency levels of the companies, which are in the top ranks according to the total premium production in the years examined, are generally at good levels, in some years, the opposite process has also been experienced. Accordingly, companies should increase their profitability and premium production by using their employment numbers and insurance policy numbers more efficiently.
\end{abstract}

Keywords

Efficiency

Turkish Insurance Sector

Data Envelopment Analysis

About Article

Received: 28.08.2021

Accepted: 15.12 .2021

Doi: $10.18026 /$ cbayarsos. 988137 


\section{Giriş}

Benzer nitelikteki risk ve tehlikeyle karşı karşıya olan kişi ve/veya kurumların, bu risk ve tehlikelere maruz kalma ihtimali sebebiyle belirli miktarda para ödenilerek toplanan tutarın, sadece o tehlikenin meydana gelmesi durumunda fiili olarak zarara uğrayanların kaybını karşılama kapsamında kullanılan bir risk transfer sistemi olarak sigortacilık sistemi ile kişiler/kurumlar, yaşam içinde karşı karşıya kaldıkları olası tehlikelerin sonucu ortaya çıkacak parayla ölçülebilen zararlarını, bu zarar karşısında nispeten küçük miktarlarda ödedikleri primler vasıtasıyla paylaşmaktadır (Herand ve Öztunç, 2014, s.189).

Finansal sistemin önemli unsurlarından biri olan sigortacılık sektörü gerek dünyada gerekse ülkemizde hızla büyüyen sektörlerin başında gelmektedir. Bireyler ve kurumlar günümüzde gittikçe artan ve çeşitlenen risk unsurları karşısında sigortacılık sistemine daha fazla yönelmekte, maddi ve manevi olarak kendilerini güvence altına alma ihtiyacı duymaktadırlar. Bu kapsamda Türkiye'de sigortacılık sektöründe son yıllarda üretilen poliçe sayısı ve prim rakamları ile birlikte sektördeki aktif büyüklügüu, karlılık, büyüme oranları, istihdam edilen personel sayısı gibi göstergelerin gün geçtikçe arttığı gözlenmektedir (Çatıkkaş ve Duramaz, 2020: 89). Nitekim sigortacılık sektörüne fonksiyonel açıdan bakıldığında sigortacılığın bünyesinde bir dayanışma unsurunun olmasının yanında aynı zamanda tasarruf kaynağ olması, yatırım fonlarına kaynak sağlaması ve sermaye piyasasının gelişimine katkı sağlaması gibi özellikleri düşünüldüğünde Türk sigortacılık sektörü özelinde hem sektörel gelişimin takip edilmesi, hem de ülke ekonomisine sağladığı katkının gözlenmesi noktasında sektöre yönelik performans analizlerinin gerçekleştirilmesi yüksek bir önem ifade etmektedir.

Sigorta ve bireysel emeklilik sektörü \%4,7 pay ile finans sektöründe bankacılı̆̆ın ardından ikinci sırada yer almaktadır. Bu kapsamda gerek çalışmada ele alınan yıllara ait sigortacılık verilerinin sunulması, gerekse sektördeki güncel tabloyu ortaya koyması açısından sigortacılık sektöründe 2018 yılında bir önceki yıla göre prim üretimi\%17,4 oranında artışla 54,7 milyar TL olmuş, bununla beraber sektördeki toplam aktif büyüklüğü 2018 yılında \%17,1 oranında artışla 178,4 milyar TL'ye yükselmiştir. Aynı şekilde 2019 yılı için bakıldı̆̆ında da toplam prim üretimi \%26,7 artışla 69,3 milyar TL olurken, sektördeki aktif büyüklüğü 2019 yılında \%32,6 oranında artışla 236,6 milyar TL'ye ulaşmıştır. Yine sektördeki karlılıklara bakıldığında ise 2018 yılında hayat ve emeklilik, hayat dışı ve reasürans alanındaki toplam karlılık 5,6 milyar lira iken bu rakam 2019' da 7,9 milyar lira dolaylarında gerçekleşmiştir (TSB, 2018; TSB, 2019).

Ulaşılan rakamsal büyüklük ve büyüyen hacimlerden hareketle sektör temsilcilerine ve araştırmacılara yol gösterme ve kaynak sağlama noktasında çalışmada 2016-2019 yılları arasında Türk sigortacılık sektörünün performansını ortaya çıkarmaya yönelik veri zarflama analizi ile etkinlik analizi gerçekleştirilmiştir. Böylelikle sektöre yönelik bir mevcut durum tablosu ortaya çıkarma ve gelecek perspektifi sunulması amaçlanmıştır. Çalışmada öncelikle sigortacılık sektörüne yönelik akademik yazında gerçekleştirilen etkinlik analizleri derlenmiş, sonrasında çalışmanın yöntemi sunulmuştur. Son bölümde ise etkinlik analizi olarak tercih edilen veri zarflama analizi aracılığıyla, Türk sigortacılık sektörünün etkinlik skorları sunulmuştur.

\section{Literatür}

Sigortacılık sektörüne yönelik gerçekleştirilen verimlilik ve etkinlik analizleri kapsamındaki ulusal ve uluslararası literatür incelendiğinde, kullanılan yöntem, araştırma örneklemi ele 
alınan değişkenler gibi birtakım göstergeler açısından benzer ve/veya farklı bazı bulguların varlığı gözlenmiş, bu çerçevede aşağıdaki çalışmalar derlenmiştir.

Öncelikle kullanılan yöntem açısından incelendiğinde sigortacılık sektöründe kullanılan ve sektörün performansını ortaya çıkarmaya yönelik verimlilik ve etkinlik ölçümünde çeşitli analiz yöntemleri karşımıza çıkmaktadır. Bu kapsamda ilk olarak veri zarflama analizi ile etkinlik analizlerinin gerçekleştirildiği çalışmalar yoğunlukla görülmektedir (Çiftçi, 2004; Başkaya ve Akar, 2005; Kılınç, 2009; Dalk1lıç, 2012; Babatunde and Haron, 2015, Ayhan ve Özcan, 2018; Tezergil, 2018; Sharew and Fentie, 2018; Dash and Muthyala, 2018). Bununla beraber korelasyon analizi (Özcan, 2019), kümeleme analizi (Başkır, 2015), finansal oran analizi (Çağlar ve Öztaş, 2016, Çakmak ve Hayırsever Baştürk, 2019), Topsis yöntemi gibi (Aydın, 2019; Yıldırım ve Altan, 2019) yöntemler kullanılarak gerçekleştirilen performans analizi çalışmalar da literatürde mevcuttur.

Örneklem açısından bakıldığında ise literatürde sigortacılık sektörünün tamamının ya da farklı sermaye gruplarının, ayrıca yine alt sigortacılık türlerinin incelendiği ve etkinlik analizi ile araştırıldığı çalışmalar söz konusudur. Bu noktada Kar ve Şahin (2018), Türkiye' de faaliyet gösteren yerli ve yabancı sermayeli tüm hayat dışı sigorta şirketlerinin etkinliklerini veri zarflama analizi ile incelemiştir. Salimi Altan (2010) ve Dalkılıç (2012) ise Türkiye' de hayat dışı faaliyet gösteren sigorta şirketlerinin etkinliklerini farklı yılları ele alarak veri zarflama analizi ile değerlendirilmiştir. Waghavkar ve Sananse (2018), Hindistan' da kamusal ve özel hayat sigortacılığ 1 şirketlerini 2011-2016 periyodunda analiz etmiştir. Yazarlar, 80.000 araç sigortası verisi ile risk, maliyet ve gelirlerin veri zarflama analizini gerçekleştirmiştir. Benyoussef ve Hemrit (2019) ise İslami sigortacılık anlayışıyla tekafül şirkeleri olarak isimlendirilen sistemdeki kuruluşlar ve diğer sigorta şirketleriyle Suudi Arabistan'daki 23 sigorta şirketi verileri üzerinden bir etkinlik analizi gerçekleştirmiş̧ir.

Sigortacılık sektörüne yönelik literatür kapsamında değerlendirilen çalışmalara ait kullanılan örneklem büyüklüğü, girdi ve çıktılar, incelenen dönem ve ülke açısından farklılıklar Tablo 1 'de verilmiştir. 
Türkiye'de Sigortacılığın Son Yıllardaki Gelişim Eğiliminin Değerlendirilmesi: 20162019 Yılları Arası Dönem İçin Sigortacılık Sektörüne Yönelik Bir Etkinlik Analizi

Tablo 1. Sigortacılık Sektörüne Yönelik Etkinlik Analizi Literatür Tablosu

\begin{tabular}{|c|c|c|c|c|c|c|}
\hline Yazarlar & Metodoloji & $\begin{array}{l}\text { İncelenen } \\
\text { ülke }\end{array}$ & $\begin{array}{l}\text { Incelenen } \\
\text { dönem }\end{array}$ & $\begin{array}{l}\text { Örneklem } \\
\text { büyüklüğü }\end{array}$ & $\begin{array}{l}\text { Kullanilan } \\
\text { girdiler }\end{array}$ & $\begin{array}{l}\text { Kullanılan } \\
\text { çıktılar }\end{array}$ \\
\hline $\begin{array}{l}\text { Segovia- } \\
\text { Gonzalez et } \\
\text { al., } 2006\end{array}$ & $\begin{array}{l}\text { Veri } \\
\text { zarflama } \\
\text { analizi }\end{array}$ & İspanya & 2002 & $\begin{array}{l}\text { Bir sigorta } \\
\text { şirketine } \\
\text { ait } 80.000 \\
\text { araç } \\
\text { sigortası } \\
\text { verisi }\end{array}$ & $\begin{array}{l}\text {-Tazminat } \\
\text { talepleri } \\
\text {-Tazminat } \\
\text { taleplerinin } \\
\text { maliyeti } \\
\text {-Sigoralının } \\
\text { sorumlu } \\
\text { olduğu } \\
\text { tazminat } \\
\text { taleplerinin } \\
\text { sayısı }\end{array}$ & $\begin{array}{l}\text {-100 sigortalı } \\
\text { başına brüt } \\
\text { prim } \\
\text {-100 sigortalı } \\
\text { başına net } \\
\text { prim }\end{array}$ \\
\hline Altan, 2010 & $\begin{array}{l}\text { Veri } \\
\text { zarflama } \\
\text { analizi }\end{array}$ & Türkiye & 2005-2007 & $\begin{array}{l}25 \text { sigorta } \\
\text { şirketine } \\
\text { ait hayat } \\
\text { dişı sigorta } \\
\text { verisi }\end{array}$ & $\begin{array}{l}\text {-Nakit ve } \\
\text { nakit benzeri } \\
\text { varlıklar } \\
\text {-Maddi } \\
\text { varlıklar } \\
\text {-Finansal } \\
\text { yatırımlar } \\
\text {-Faaliyet } \\
\text { borçları } \\
\text {-Sigortacılık } \\
\text { teknik } \\
\text { karşılıkları } \\
\text {-Ödenmiş } \\
\text { sermaye }\end{array}$ & $\begin{array}{l}\text {-Esas } \\
\text { faaliyetlerden } \\
\text { alacaklar } \\
\text {-Dönem net } \\
\text { karı/zararı }\end{array}$ \\
\hline $\begin{array}{l}\text { Dalkılıç, } \\
2012\end{array}$ & $\begin{array}{l}\text { Veri } \\
\text { zarflama } \\
\text { analizi }\end{array}$ & Türkiye & $2008-2010$ & $\begin{array}{l}27 \text { hayat } \\
\text { dışı sigorta } \\
\text { şirketine } \\
\text { ait veri }\end{array}$ & $\begin{array}{l}\text {-öz kaynaklar } \\
\text {-çalışan sayısı } \\
\text {-acente sayısı } \\
\text {-sabit } \\
\text { varlıklar (net) }\end{array}$ & $\begin{array}{l}\text {-toplam } \\
\text { sigortacılık } \\
\text { teknik } \\
\text { karşılıkları } \\
\text { (net) } \\
\text {-toplam prim } \\
\text { üretimi } \\
\text {-ödenen } \\
\text { tazminatlar } \\
\text { toplamı (net) }\end{array}$ \\
\hline $\begin{array}{l}\text { Babatunde } \\
\text { ve Haron, } \\
2015\end{array}$ & $\begin{array}{l}\text { Veri } \\
\text { zarflama } \\
\text { analizi }\end{array}$ & Nijerya & 2008-2012 & $\begin{array}{l}10 \text { sigorta } \\
\text { şirketine } \\
\text { ait veri }\end{array}$ & $\begin{array}{l}\text {-Komisyonlar } \\
\text {-Yönetim } \\
\text { giderleri }\end{array}$ & $\begin{array}{l}\text {-Prim } \\
\text { kazançları } \\
\text {-Yatırım } \\
\text { gelirleri }\end{array}$ \\
\hline
\end{tabular}




\begin{tabular}{|c|c|c|c|c|c|c|}
\hline $\begin{array}{l}\text { Dash ve } \\
\text { Muthyala, } \\
2018\end{array}$ & $\begin{array}{l}\text { Veri } \\
\text { zarflama } \\
\text { analizi }\end{array}$ & Hindistan & $2010-2017$ & $\begin{array}{l}15 \text { sigorta } \\
\text { şirketi } \\
\text { hayat } \\
\text { sigorta } \\
\text { verisi }\end{array}$ & $\begin{array}{l}\text {-Komisyon } \\
\text { giderleri } \\
\text {-̇̇sletme } \\
\text { giderleri } \\
\text {-Net ödenen } \\
\text { karlar }\end{array}$ & $\begin{array}{l}\text {-Bireysel ve } \\
\text { toplu olarak } \\
\text { sigorta } \\
\text { primleri }\end{array}$ \\
\hline $\begin{array}{l}\text { Tezergil, } \\
2018\end{array}$ & $\begin{array}{l}\text { Veri } \\
\text { zarflama } \\
\text { analizi }\end{array}$ & Türkiye & 2014-2016 & $\begin{array}{l}27 \text { sigorta } \\
\text { şirketine } \\
\text { ait veri } \\
\text { (ortalama) }\end{array}$ & $\begin{array}{l}\text {-Özkaynak } \\
\text { karlılığı } \\
\text {-Toplam } \\
\text { gider/prim } \\
\text {-Acente, } \\
\text { broker ve } \\
\text { banka acente } \\
\text { sayısı }\end{array}$ & $\begin{array}{l}\text { - Dönem net } \\
\text { karı/zararı } \\
\text {-Toplam prim } \\
\text { üretimi } \\
\text {-Toplam } \\
\text { tazminat } \\
\text { ödemeleri }\end{array}$ \\
\hline $\begin{array}{l}\text { Sharew and } \\
\text { Fentie, } 2018\end{array}$ & $\begin{array}{l}\text { Veri } \\
\text { zarflama } \\
\text { analizi }\end{array}$ & Etiyopya & 2006-2015 & $\begin{array}{l}9 \text { sigorta } \\
\text { şirketine } \\
\text { ait veri }\end{array}$ & $\begin{array}{l}\text {-Toplam } \\
\text { aktifler } \\
\text {-Toplam } \\
\text { Giderler }\end{array}$ & $\begin{array}{l}\text {-Vergi sonrasi } \\
\text { net kar } \\
\text {-Toplam } \\
\text { sigorta primi }\end{array}$ \\
\hline $\begin{array}{l}\text { Waghavkar } \\
\text { ve Sananse, } \\
2018\end{array}$ & $\begin{array}{l}\text { Veri } \\
\text { zarflama } \\
\text { analizi }\end{array}$ & Hindistan & 2011-2016 & $\begin{array}{l}1 \text { kamusal } \\
\text { ve } 13 \text { özel } \\
\text { sigorta } \\
\text { şirketine } \\
\text { ait veri }\end{array}$ & $\begin{array}{l}\text {-Komisyon } \\
\text { giderleri } \\
\text {-Yönetim } \\
\text { giderleri }\end{array}$ & $\begin{array}{l}\text {-Yatırım } \\
\text { gelirleri }\end{array}$ \\
\hline $\begin{array}{l}\text { Ayhan ve } \\
\text { Özcan, } 2018\end{array}$ & $\begin{array}{l}\text { Veri } \\
\text { zarflama } \\
\text { analizi }\end{array}$ & Türkiye & 2010-2016 & $\begin{array}{l}32 \text { sigorta } \\
\text { şirketine } \\
\text { ait veri }\end{array}$ & $\begin{array}{l}\text {-Teknik } \\
\text { giderler } \\
\text {-Maddi } \\
\text { varlıklar }\end{array}$ & $\begin{array}{l}\text {-Teknik } \\
\text { gelirler } \\
\text {-Prim } \\
\text { üretimleri }\end{array}$ \\
\hline $\begin{array}{l}\text { Benyoussef } \\
\text { ve Hemrit, } \\
2019\end{array}$ & $\begin{array}{l}\text { Veri } \\
\text { zarflama } \\
\text { analizi }\end{array}$ & $\begin{array}{l}\text { Suudi } \\
\text { Arabistan }\end{array}$ & & $\begin{array}{l}23 \text { tekafül } \\
\text { ve diğer } \\
\text { sigorta } \\
\text { şirketine } \\
\text { ait veri }\end{array}$ & $\begin{array}{l}\text {-Yatırımlar } \\
\text {-Hasar } \\
\text { talepleri }\end{array}$ & $\begin{array}{l}\text {-Sermaye } \\
\text {-Sigorta } \\
\text { primleri }\end{array}$ \\
\hline
\end{tabular}

Kaynak: Yazar tarafından derlenmiştir.

Tablo 1 incelendiğinde, öncelikle girdiler ve çıtılar açısından literatürde bu noktada bir birlikteliğin bulunmadığı, çalışmalarda farklı çalışmalarda farklı girdi ve çıktı kriterleri kullanıldığı görülmektedir. Buna göre ele alınan çalışmalarda en çok kullanılan girdi ve çıktı değişkenleri arasında sigorta primleri, işlem adeti ve büyüklükleri, gelir, gider ve karlılık verileri, hasar verileri, tazminat bilgileri gibi temel kriterlerin kullanıldığ1 görülmektedir. Bununla birlikte incelenen dönemlerle ilgili de literatürde farklı süre dilimlerinin baz alındığ görülmektedir. Buna göre bazı çalışmalarda tek bir yılın verileri üzerinden hareket edilmekteyken, bazı çalışmalarda birden fazla yıl değerlendirmeye alınmıştır. 


\section{Yöntem}

Gerek çalışmada sunulan literatürde görüldügüü üzere gerekse farklı bilim dallarında etkinlik ve verimlilik gibi unsurların performans çıktısı olarak ölçülmesi ve bu ölçümlerde farklı tekniklerin kullanılması söz konusudur. Bu kapsamda sosyal bilimler alanında geçmiş verilere göre geleceğe yönelik tahminler çıaran ve aynı zamanda parametrik metotlardan oluşan regresyon analizi, muhasebe, bankacılık, sigortacılık gibi alanlarda kuruluşların mali verilerini belli bir sıra düzenine göre oranlamayı esas alan oran analizi, eğitim, sağlık, finans gibi farklı sektörlerde yaygın bir şekilde kullanılan parametrik olmayan veri zarflama analizi teknikleri mevcuttur (Kutlar ve Kartal, 2004, s.52, Duramaz, 2018).

Çalışmada etkinlik analiz yöntemi olarak veri zarflama analizi tercih edilmiştir. "Çok Amaçlı Karar Alma Yöntemlerinden" biri olan "Veri Zarflama Analizi (Data Envelopment Analysis)" ilk olarak 1957 yılında Michael James Farrell tarafından geliştirilmiş. İlk ortaya çıkışında üretim tekniklerinin analizinde kullanılmıştır. Daha sonra Abraham Charnes, William W. Cooper ve Edwardo Rhodes 1978 yılında, etkinlik ölçümünde matematiksel olarak modelleme yaparak analizi bir ileriki aşamaya taşımıştır (Cooper vd., 1978; Tezergil, 2018, s.345).

Veri zarflama analizi, "Karar Verme Birimleri” olarak geçen yani örneklem olarak belirlenen ve birbiri ile aynı ya da benzer girdiler kullanarak onlar aracılığıyla benzer çıktıları üreten işletmeleri/kurum ve-veya kuruluşları karşılaştırarak göreli olarak verimliliğini ölçerek etkinlik analizi yapabilen "firmalar arası karşılaştırma modeli" olarak ifade edilebilir (Babacan ve Özcan, 2009, s.177).

VZA uygulama aşamaları şu şekildedir (Tezergil, 2018, s.345):

a. "Karar verme birimlerinin seçilmesi,

b. Girdi ve çıtı değişkenlerinin belirlenmesi,

c. Uygun VZA modelinin seçilmesi,

d. Etkinlik Değerlerinin Belirlenmesi

e. Referans Kümelerinin Belirlenmesi,

f. Etkin Olmayan Karar Verme Birimleri İçin Stratejilerin belirlenmesi" aşamalarından oluşmaktadır.

VZA modelde kullanılacak karar birimlerinden göreceli olarak etkin bir sinır belirler ve bu sınıra uzaklığına göre diğer karar birimleri için etkinlik hesaplaması yapar. Etkinlik skoru 0 ile 1 arası bir değer alır, 0 'dan 1 'e gidildikçe etkinliğin arttığı izlenir. Yöntem uygulandıktan sonra elde edilen sonuçlardan hareketle etkin karar birimleri benchmark olarak seçilerek yönetimin karar sürecinde destek olarak kullanılabilir (Tarkoçin ve Gençer , 2010, s.21).

VZA modellerinden en yaygın olanı ve aynı zamanda daha fazla uygulama alanına sahip olanlar Charnes, Cooper ve Rhodes (1978)'un geliştirdiği CCR modeli ile Banker, Charnes ve Cooper (1984) tarafından geliştirilen BCC modelleridir. Modeller, modeli geliştiren kişilerin baş harflerinden oluşmaktadır. Uygulama bölümünde tercih edilen CCR modeli ölçeğe göre getirinin sabit olduğu varsayımıyla toplam etkinliğin belirlenmesini sağlar. BCC modeli de ölçeğe göre değişken getiri varsayımı ile teknik etkinliği belirlemektedir. Ölçeğe göre getiri, çıktı miktarlarında ortaya çıkan değişikliklerin girdi miktarlarındaki değişiklikler nedeniyle ortaya çıkması olarak ifade edilir. Eğer girdi miktarlarında oluşan bir artış ile çıtı miktarlarındaki artış oransal olarak aynıysa ölçeğe göre sabit getiri söz konusudur; çıktı 
miktarlarındaki artış oransal olarak girdi miktarına göre daha yüksek olduğunda ölçeğe göre artan getiri söz konusudur; çıtı miktarlarındaki artış oransal olarak daha düşük ise de ölçeğe göre azalan getiri söz konusudur (Charnes vd., 1978, Altan, 2010, s.193, Bakhshoodeh ve Thomson, 2001, s.310; Özçelik ve Öztürk,2019,s.1017, Yalçınkaya ve Duramaz, 2021, s.213).

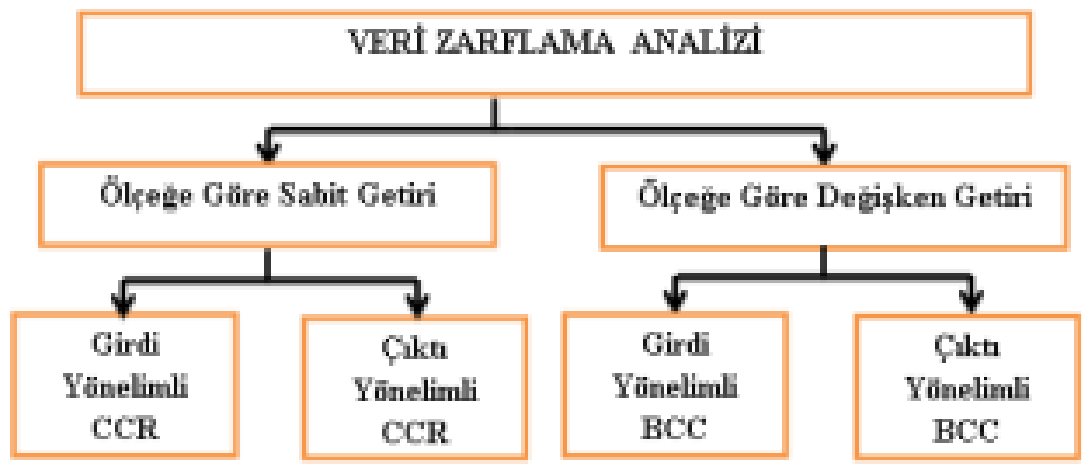

Şekil 1. Veri Zarflama Analizi Türleri

Kaynak: Akyüz vd., 2015, s.51.

Şekil 1'de de görüleceği üzere ölçeğe göre artan getiri ve ölçeğe göre azalan getiri girdi odaklı (yönelimli) ve çıtı odaklı (yönelimli) olarak değerlendirilmektedir. Bu noktada "girdi odaklılık", çıtı miktarlarının sabit tutularak girdi miktarlarındaki değişikliklere kapsamında analizin yapılmasıdır; girdi miktarlarının sabit tutularak, çıtı miktarlarındaki değişikliklere göre analizin yapılması da "çıktı odaklılık"tır (Tarkoçin ve Gençer, 2010, s.21).

Tüm doğrusal programlama modelleri gibi VZA modelleri de primal ve dual olmak üzere iki farklı formda ifade edilebilir. Veri zarflama analizinde dual model, primal modele göre en iyi çözüme ulaşmak için hem daha az matematiksel işlem gerektirdiğinden, hem de önemli yönetsel bilgiler sağladığından daha çok kullanılmaktadır (Özden, 2008, s.171).

\begin{tabular}{|l|l|l|l|}
\hline Girdi Yönelimli CCR Modelleri & \multicolumn{2}{|l|}{ C,ktı Yönelimli CCR Modelleri } \\
\hline Primal & Dual & Primal & Dual \\
\hline$E n b \sum_{r=1}^{s} u_{r} Y_{r k}$ & Enk $\theta_{\mathrm{k}}$ & Enk $\sum_{i=1}^{m} v_{i} . X_{i k}$ & Enb $Z_{\mathrm{k}}$ \\
$\sum_{r=1}^{s} u_{r} Y_{r j}-\sum_{i=1}^{m} v_{i} X_{i j} \leq 0$ & $\sum_{j=1}^{n} \lambda_{j k} X_{i j} \leq \theta_{k} X_{i k}$ & $\sum_{j=1}^{m} \eta_{j k} X_{i j} \leq X_{i k}$ \\
$\sum_{i=1}^{m} v_{i} X_{i k}=1$ & $\sum_{j=1}^{n} \lambda_{j k} Y_{r j} \geq Y_{r k}$ & $\sum_{i} v_{i j}-\sum_{r=1}^{s} u_{r} Y_{r j} \geq 0$ & $Z_{k} Y_{r k}-\sum_{j=1}^{n} \eta_{j k} Y_{r j} \leq 0$ \\
$u_{r}, v_{i} \geq 0$ & $\lambda_{j k} \geq 0$ & $\sum_{r=1}^{s} u_{r} Y_{r k}=1$ & $\eta_{j k} \geq 0$ \\
\hline
\end{tabular}

Şekil 2. CCR Modelleri

Kaynak: Cooper vd. 2004, akt. Özden, 2008, s.173. 


\begin{tabular}{|l|l|l|l|}
\hline \multicolumn{2}{|l|}{ Girdi Yönelimli BCC Modelleri } & \multicolumn{2}{l|}{ Çıktı Yönelimli BCC Modelleri } \\
\hline Primal & Dual & Primal & Dual \\
\hline Enk $\theta_{k}$ & $E n b \sum_{r=1}^{s} u_{r} Y_{r k}-u_{k}$ & Enb $\mathrm{Z}_{\mathrm{k}}$ & Enk $\sum_{i=1}^{m} v_{i} X_{i k}-v_{k}$ \\
$\theta_{k} X_{i k}-\sum_{j=1}^{n} \lambda_{j k} X_{i j} \geq 0$ & $\sum_{k} Y_{r k}-\sum_{j=1}^{n} \eta_{j k} Y_{r j} \leq 0$ & $-\sum_{r=1}^{s} u_{r} Y_{r j}+\sum_{i=1}^{m} v_{i} X_{i j}-v_{k}$ \\
$\sum_{j=1}^{n} \lambda_{j k} Y_{r j} \geq Y_{r k}$ & $\sum_{r=1}^{m} u_{r j}-\sum_{i=1}^{m} v_{i} X_{i j}-u_{k} \leq 0$ & $\sum_{j=1}^{n} \eta_{j k} X_{i j} \leq X_{i k}$ & $\sum_{i=1}^{m} u_{r} Y_{r k}=1$ \\
$\sum_{j=1}^{n} \lambda_{j k}=1$ & $\sum_{i=1}^{n} v_{i} X_{i k}=1$ & $\sum_{j=1}^{n} \eta_{j k}=1$ & $n_{i} \geq \varepsilon>0, \mathbf{v}_{\mathrm{k}}$ serbest \\
$\lambda_{j k} \geq 0$ & $u_{j k} \geq 0$ & & \\
\hline
\end{tabular}

Şekil 3. BCC Modelleri

Kaynak: Cooper vd. 2004, akt. Özden, 2008, s.174.

\section{Uygulama}

Yöntem bölümünde de görüleceği üzere veri zarflama analizinin ilk aşamasını karar verme birimlerinin seçilmesi oluşturmaktadır. Buna göre araştırmada karar verme birimi olarak Türk sigortacılık sektöründe toplam prim üretimine göre pazar payı sıralamasında en üst sırada yer alan ilk 14 şirket seçilmiştir. Veri zarflama analizinde etkinlik değerlerinin güvenilir olması karar verme birimlerinin sayısının da girdi-çıktı sayısından daha fazla olması ve bu yönde artırılması beklenmektedir (Akgöbek vd., 2015, s.50). Bu kapsamda çalışma, ilgili şirketlerin 2016-2019 dönemine ait etkinlik performansının veri zarflama analizi ile incelenmesi üzerine kurulmuştur. Bu kapsamda 2016-2019 yılları arasında analize dahil edilen sigorta şirketleri Tablo 2'de verilmiştir. 
Tablo 2. Analize Dahil Edilen Sigorta Şirketleri

\begin{tabular}{lc}
\hline 1 & Allianz Sigorta AŞ \\
2 & Anadolu Anonim Türk Sigorta Şirketi \\
3 & Aksigorta AŞ \\
4 & Axa Sigorta AŞ \\
5 & Sompo Sigorta AŞ \\
6 & HDI Sigorta AŞ \\
7 & Mapfre Sigorta AŞ \\
8 & Ziraat Sigorta AŞ \\
9 & Güneş Sigorta AŞ \\
10 & Halk Sigorta AŞ \\
11 & Neova Sigorta AŞ \\
12 & Bupa Acibadem Sigorta AŞ \\
13 & Doga Sigorta AŞ \\
14 & Eureko Sigorta AŞ \\
\hline
\end{tabular}

Tablo 2'de şirketler, ürettikleri toplam prim miktarına göre pazarda sahip oldukları büyüklüklerine göre tabloda sıralanmıştır. Emeklilik şirketleri kapsam dışındadır.

Veri zarflama analizinin gerçekleştirilebilmesi için ikinci aşama girdi ve çıktı değişkenlerinin belirlenmesi sürecidir. Etkinlik analizinin gerçekleştirilmesi için çalışan sayısı, üretilen poliçe adeti ve sigorta şirketlerinde istihdam edilen personel sayıları olmak üzere 2 adet girdi, toplam prim üretimi ve dönem net karı rakamları olmak üzere 2 adet çıtı seçilerek (Bkz. Tablo 3) sektöre yönelik etkinlik analizi gerçekleştirilmiştir.

Tablo 3. Sigorta Şirketlerinin Etkinlik Analizi Için Belirlenen Girdi ve Çıktı Değişkenleri

\begin{tabular}{cc}
\hline Girdiler & Çıtıtılar \\
\hline İstihdam & Prim üretimi \\
Poliçe adet & Dönem net karı/zararı \\
\hline
\end{tabular}

Girdi ve çıktıların belirlenmesinde performans şirket bünyesinde istihdam miktarının ve üretilen poliçe adetlerinin artması ya da azalması reelde hem sektördeki üretilen prim miktarlarını hem de karlılıkları arttırabilmekte ya da azaltabilmektedir. Dolayısıyla analize dahil edilen değişkenlerin belirlenmesinde hem değişkenler arası ilişkilerin reeldeki yansımalarına hem de literatüre göre hareket edilmiştir. Analizde kullanılan veriler, Türkiye Sigorta Birliği internet sitesinden derlenmiştir (TSB, 2021).

Veri zarflama analizi ile etkinlik analizinin gerçekleştirilmesinde DEAP 2.1 programı kullanılmıştır. Seçilen ve girdi değişkenleri kapsamında CCR modelinde girdi yönelimli veri zarflama analizi yöntemi çerçevesinde etkinlik analizi gerçekleştirilmiştir. 


\section{Bulgular}

14 sigorta şirketinin 2016-2019 y1llarındaki etkinlik skorları veri zarflama analizine tabi tutularak Tablo 4'te verilmiştir. Buna göre genel olarak analiz sonuçları değerlendirildiğinde incelenen tüm yıllarda genel olarak etkinlik skoru olarak tam etkinlik düzeyine yakın bir performans göstermişlerdir. Ziraat Sigorta AŞ tüm yıllarda etkinliği sağlamış tek sigorta şirketidir. Allianz Sigorta AŞ’nin üretilen prim miktarına göre sektörde ilk sırada yer alması ile örtüşecek şekilde, analiz sonuçlarına göre etkinlik düzeyinin 2019 yılı dışında her yıl tam etkinlik düzeyine ulaştı̆̆ görülmektedir.

Tablo 4. 2016-2019 Yılları Sigorta Şirketleri Etkinlik Skorları

\begin{tabular}{ccccc}
\hline Y1//Karar Verme Birimi & $\mathbf{2 0 1 6}$ & $\mathbf{2 0 1 7}$ & $\mathbf{2 0 1 8}$ & $\mathbf{2 0 1 9}$ \\
\hline Allianz Sigorta AŞ & 1.000 & 1.000 & 1.000 & 0.820 \\
Anadolu Anonim Türk Sigorta Şirketi & 0.974 & 0.989 & 0.869 & 0.855 \\
Aksigorta AŞ & 0.693 & 0.943 & 0.876 & 1.000 \\
Axa Sigorta AŞ & 1.000 & 0.906 & 0.883 & 0.901 \\
Sompo Sigorta AŞ & 0.877 & 0.867 & 0.839 & 0.797 \\
HDI Sigorta AŞ & 0.701 & 0.816 & 1.000 & 0.732 \\
Mapfre Sigorta AŞ & 1.000 & 1.000 & 0.807 & 0.854 \\
Ziraat Sigorta AŞ & 1.000 & 1.000 & 1.000 & 1.000 \\
Güneş Sigorta AŞ & 0.777 & 0.750 & 0.644 & 0.600 \\
Halk Sigorta AŞ & 0.787 & 0.871 & 0.883 & 0.960 \\
Neova Sigorta AŞ & 1.000 & 0.873 & 0.774 & 0.780 \\
Bupa Acıbadem Sigorta AŞ & 1.000 & 0.862 & 1.000 & 1.000 \\
Doga Sigorta AŞ & 0.876 & 1.000 & 0.798 & 0.729 \\
Eureko Sigorta AŞ & 0.662 & 1.000 & 0.551 & 0.411 \\
\hline
\end{tabular}

Aynı şekilde Tablo 4'e göre üretilen prim miktarına göre sektörde son sırada yer alan Eureko Sigorta AŞ de etkinlik skoru olarak 2017 yılı hariç en düşük performansa sahip sigorta şirketi olarak gözlenmiştir. Buna göre veri zarflama analizi uygulama aşamaları arasında yer alan referans kümeleri de ortaya çıkmaktadır. Yıl içinde tam etkinlik düzeyine ulaşan sigorta şirketleri diğer şirketler açısından referans kümesi içinde yer almaktadırlar.

Örneklem olarak seçilen Sigorta şirketlerinin 2016 yılına ait etkinlik skorları Tablo 5'te verilmiştir. Buna göre Allianz Sigorta AŞ, Axa Sigorta AŞ, Maphre Sigorta AŞ, Ziraat Sigorta AŞ, Neova Sigorta AŞ ve Bupa Acıbadem Sigorta AŞ’nin performansları tam etkinlik skoru olan 1'e ulaşmiştır. 
Tablo 5. 2016 yılı Sigorta Şirketlerine ait Gerçekleşen ve Olması Gereken Girdi Değerleri

\begin{tabular}{|c|c|c|c|c|c|}
\hline Sigorta Şirketleri-2016 & Değişkenler & Değişkenler & Gerçekleşen & Hedef & Fark \\
\hline \multirow[b]{2}{*}{ Allianz Sigorta AŞ } & \multirow{2}{*}{ Girdiler } & İstihdam & 1584 & - & - \\
\hline & & Poliçe adet & 6153451 & - & - \\
\hline \multirow[t]{2}{*}{ Anadolu Anonim Türk Sigorta Şirketi } & \multirow{2}{*}{ Girdiler } & İstihdam & 1185 & 1154 & -31 \\
\hline & & Poliçe adet & 4805013 & 4679241 & -125771853 \\
\hline \multirow[t]{2}{*}{ Aksigorta AŞ } & \multirow{2}{*}{ Girdiler } & İstihdam & 611 & 423 & -188 \\
\hline & & Poliçe adet & 3379316 & 2341039 & -1038277 \\
\hline \multirow{2}{*}{ Axa Sigorta AŞ } & \multirow{2}{*}{ Girdiler } & İstihdam & 730 & - & - \\
\hline & & Poliçe adet & 4907266 & - & - \\
\hline \multirow[t]{2}{*}{ Sompo Sigorta AŞ } & \multirow{2}{*}{ Girdiler } & İstihdam & 466 & 409 & -57 \\
\hline & & Poliçe adet & 4691647 & 4113464 & -578182 \\
\hline \multirow[t]{2}{*}{ HDI Sigorta AŞ } & \multirow{2}{*}{ Girdiler } & İstihdam & 287 & 207 & -86 \\
\hline & & Poliçe adet & 1533154 & 1074822 & -458332 \\
\hline \multirow[t]{3}{*}{ Mapfre Sigorta AŞ } & \multirow{3}{*}{ Girdiler } & İstihdam & 689 & - & - \\
\hline & & Poliçe adet & 1949042 & - & - \\
\hline & & İstihdam & 189 & - & - \\
\hline \multirow[t]{2}{*}{ Ziraat Sigorta AŞ } & \multirow[t]{2}{*}{ Girdiler } & Poliçe adet & & & \\
\hline & & & 3369760 & - & - \\
\hline \multirow[t]{2}{*}{ Güneş Sigorta AŞ } & & İstihdam & 599 & 465 & -134 \\
\hline & Girdiler & Poliçe adet & 1691015 & 1313283 & -377732 \\
\hline \multirow[b]{2}{*}{ Halk Sigorta AŞ } & \multirow{2}{*}{ Girdiler } & İstihdam & 244 & 192 & -52 \\
\hline & & Poliçe adet & 2268852 & 1786355 & -482497 \\
\hline \multirow[t]{2}{*}{ Neova Sigorta AŞ } & \multirow{2}{*}{ Girdiler } & İstihdam & 232 & - & - \\
\hline & & Poliçe adet & 1424576 & - & - \\
\hline \multirow[t]{2}{*}{ Bupa Acıbadem Sigorta AŞ } & \multirow{2}{*}{ Girdiler } & İstihdam & 312 & - & - \\
\hline & & Poliçe adet & 631768 & - & - \\
\hline \multirow{2}{*}{ Doga Sigorta AŞ } & \multirow{2}{*}{ Girdiler } & İstihdam & 181 & 159 & -22 \\
\hline & & Poliçe adet & 1368599 & 1198595 & -170004 \\
\hline \multirow[t]{2}{*}{ Eureko Sigorta AŞ } & \multirow{2}{*}{ Girdiler } & İstihdam & 582 & 384 & -198 \\
\hline & & Poliçe adet & 1896035 & 1255317 & -640718 \\
\hline
\end{tabular}

2016 yılı için tam etkinlik skoruna ulaşan sigorta şirketlerinin dışındaki diğer sigorta şirketlerinin girdi yönelimli etkinlik skorları değerlendirildiğinde tam etkinlik skorlarına ulaşabilmeleri için gerekli olan hedef skorları ve farklar Tablo 5'te görülmektedir. Buna göre 2016 yılı için en düşük etkinlik skoruna sahip olduğu için Eureko Sigorta AŞ.'nin tam etkinlik 
düzeyine ulaşabilmesi için gerekli düzeltme rakamı da diğer sigorta şirketlerine göre daha fazladır. Eureko Sigorta AŞ’nin tam etkinlik düzeyine ulaşabilmesi için girdi kalemlerinden istihdamı 384 olarak, kesilen poliçe adetini de 1255317 olarak gerçekleştirmeliydi. Aynı şekilde yıl içindeki en düşük etkinlik düzeyine sahip ikinci şirket olan Aksigorta AŞ’nin de tam etkinlik düzeyine ulaşabilmesi için istihdam sayısını 423'e, poliçe sayısını da 4679241'e düşürmeliydi.

Tablo 6' da örneklem olarak seçilen sigorta şirketlerinin 2017 yılına ait etkinlik skorları tabloda verilmiştir. Tablo incelendiğinde 2017 yılı için incelenen sigorta şirketleri arasında Allianz Sigorta AŞ, Mapfre Sigorta AŞ, Ziraat Sigorta AŞ, Bupa Acıbadem Sigorta AŞ, Doga Sigorta AŞ tam etkinlik düzeyine eriştikleri gözlenmektedir.

Tablo 6. 2017 yılı Sigorta Şirketlerine ait Gerçekleşen ve Olması Gereken Girdi Değerleri

\begin{tabular}{|c|c|c|c|c|c|}
\hline Sigorta Şirketleri-2017 & Değişkenler & Değişkenler & Gerçekleşen & Hedef & Fark \\
\hline \multirow{2}{*}{ Allianz Sigorta AŞ } & \multirow{2}{*}{ Girdiler } & İstihdam & 1586 & - & - \\
\hline & & Poliçe adet & 4808632 & - & - \\
\hline \multirow[t]{2}{*}{ Anadolu Anonim Türk Sigorta Şirketi } & \multirow{2}{*}{ Girdiler } & İstihdam & 1185 & 1172 & -13 \\
\hline & & Poliçe adet & 4779643 & 4725557 & -54086 \\
\hline \multirow[t]{2}{*}{ Aksigorta AŞ } & \multirow{2}{*}{ Girdiler } & İstihdam & 611 & 576 & -35 \\
\hline & & Poliçe adet & 3655281 & 3448691 & -206590 \\
\hline \multirow{2}{*}{ Axa Sigorta AŞ } & \multirow{2}{*}{ Girdiler } & İstihdam & 730 & 662 & -68 \\
\hline & & Poliçe adet & 3936723 & 3568415 & -368308 \\
\hline \multirow[t]{2}{*}{ Sompo Sigorta AŞ } & \multirow{2}{*}{ Girdiler } & İstihdam & 466 & 404 & -62 \\
\hline & & Poliçe adet & 5033783 & 4363841 & -669942 \\
\hline \multirow{2}{*}{ HDI Sigorta AŞ } & \multirow{2}{*}{ Girdiler } & İstihdam & 287 & 234 & -53 \\
\hline & & Poliçe adet & 1819539 & 1484193 & -335346 \\
\hline \multirow[t]{3}{*}{ Mapfre Sigorta AŞ } & \multirow{3}{*}{ Girdiler } & İstihdam & 2556372 & - & - \\
\hline & & Poliçe adet & 689 & - & - \\
\hline & & İstihdam & 4249408 & - & - \\
\hline \multirow[t]{2}{*}{ Ziraat Sigorta AŞ } & \multirow[t]{2}{*}{ Girdiler } & Poliçe adet & & & \\
\hline & & & 189 & - & - \\
\hline \multirow[t]{3}{*}{ Güneş Sigorta AŞ } & \multirow{3}{*}{ Girdiler } & İstihdam & 599 & 449 & -150 \\
\hline & & Poliçe adet & 1865466 & 1398223 & -467243 \\
\hline & & İstihdam & 244 & 213 & -31 \\
\hline Halk Sigorta AŞ & Girdiler & Poliçe adet & 3405356 & 2966712 & -438644 \\
\hline \multirow[t]{2}{*}{ Neova Sigorta AŞ } & \multirow{2}{*}{ Girdiler } & İstihdam & 232 & 200 & -32 \\
\hline & & Poliçe adet & 2081932 & 1794710 & -287222 \\
\hline \multirow[t]{2}{*}{ Bupa Acıbadem Sigorta AŞ } & \multirow{2}{*}{ Girdiler } & İstihdam & 312 & - & - \\
\hline & & Poliçe adet & 191110 & - & - \\
\hline \multirow{2}{*}{ Doga Sigorta AŞ } & \multirow{2}{*}{ Girdiler } & İstihdam & 181 & - & - \\
\hline & & Poliçe adet & 3296073 & - & - \\
\hline \multirow{2}{*}{ Eureko Sigorta AŞ } & \multirow{2}{*}{ Girdiler } & İstihdam & 582 & 361 & -221 \\
\hline & & Poliçe adet & 2030565 & 1259725 & -770840 \\
\hline
\end{tabular}

Aynı şekilde Tablo 6'ya göre 2017 yılı için tam etkinlik skoruna ulaşan sigorta şirketlerinin yanında tam etkinliğe en yakın sigorta şirketleri sırasıyla Anadolu Anonim Türk Sigorta Şirketi, Aksigorta AŞ, Axa Sigorta AŞ, Neova Sigorta AŞ, Halk Sigorta AŞ, Sompo Sigorta AŞ, HDI Sigorta AŞ, Güneş Sigorta AŞ’dir. En düşük etkinlik skoruna sahip Güneş Sigorta AŞ’nin istihdam miktarını 449 olarak, poliçe miktarını da 1398223 olarak gerçekleştirseydi aynı çıktı 
düzeyleri ile tam etkinlik skoruna erişebilmesi etkinlik analizine göre mümkün gözükmektedir.

Tablo 7'de örneklem olarak seçilen sigorta şirketlerinin 2018 yılına göre girdi miktarları olan poliçe ve istihdam rakamları ile ve tam etkinlik skoruna ulaşması için gerekli hedef ve fark rakamları yer almaktadır. Buna göre 2018 yılında Allianz Sigorta AŞ, HDI Sigorta AŞ, Ziraat Sigorta AŞ, Bupa Acıbadem Sigorta AŞ tam etkinlik skoru olan 1'e ulaşmıştır.

Tablo 7. 2018 yılı Sigorta Şirketlerine ait Gerçekleşen ve Olması Gereken Girdi Değerleri

\begin{tabular}{|c|c|c|c|c|c|}
\hline Sigorta Şirketleri-2018 & Değişkenler & Değişkenler & Gerçekleşen & Hedef & Fark \\
\hline \multirow{2}{*}{ Allianz Sigorta AŞ } & \multirow{2}{*}{ Girdiler } & İstihdam & 1561 & - & - \\
\hline & & Poliçe adet & 3965901 & - & - \\
\hline \multirow[t]{2}{*}{ Anadolu Anonim Türk Sigorta Şirketi } & \multirow{2}{*}{ Girdiler } & İstihdam & 1288 & 1119 & 169 \\
\hline & & Poliçe adet & 5511703 & 4790615 & -721088 \\
\hline \multirow[t]{2}{*}{ Aksigorta AŞ } & \multirow{2}{*}{ Girdiler } & İstihdam & 647 & 567 & -80 \\
\hline & & Poliçe adet & 4378006 & 3837229 & -540777 \\
\hline \multirow{2}{*}{ Axa Sigorta AŞ } & \multirow{2}{*}{ Girdiler } & İstihdam & 673 & 594 & -79 \\
\hline & & Poliçe adet & 3696102 & 3264443 & -431659 \\
\hline \multirow[t]{2}{*}{ Sompo Sigorta AŞ } & \multirow{2}{*}{ Girdiler } & İstihdam & 612 & 514 & -98 \\
\hline & & Poliçe adet & 4371116 & 3668153 & -702963 \\
\hline \multirow[t]{2}{*}{ HDI Sigorta AŞ } & \multirow{2}{*}{ Girdiler } & İstihdam & 424 & - & - \\
\hline & & Poliçe adet & 2385536 & - & - \\
\hline \multirow[t]{3}{*}{ Mapfre Sigorta AŞ } & \multirow{3}{*}{ Girdiler } & İstihdam & 805 & 649 & -156 \\
\hline & & Poliçe adet & 1901935 & 1533943 & -367992 \\
\hline & & İstihdam & 172 & - & - \\
\hline \multirow[t]{2}{*}{ Ziraat Sigorta AŞ } & \multirow[t]{2}{*}{ Girdiler } & Poliçe adet & & & \\
\hline & & & 4626691 & - & - \\
\hline \multirow[t]{2}{*}{ Güneş Sigorta AŞ } & & İstihdam & 601 & 387 & -214 \\
\hline & Girdiler & Poliçe adet & 2268263 & 1460021 & -808242 \\
\hline & Girdilor & İstihdam & 244 & 215 & -29 \\
\hline Halk Sigorta AŞ & & Poliçe adet & 3153390 & 2785044 & -368346 \\
\hline \multirow[t]{2}{*}{ Neova Sigorta AŞ } & \multirow{2}{*}{ Girdiler } & İstihdam & 225 & 174 & -51 \\
\hline & & Poliçe adet & 2589961 & 2003377 & -586584 \\
\hline \multirow[t]{2}{*}{ Bupa Acıbadem Sigorta AŞ } & \multirow{2}{*}{ Girdiler } & İstihdam & 324 & - & - \\
\hline & & Poliçe adet & 166940 & - & - \\
\hline \multirow{2}{*}{ Doga Sigorta AŞ } & \multirow{2}{*}{ Girdiler } & İstihdam & 256 & 204 & -52 \\
\hline & & Poliçe adet & 3322341 & 2621574 & -670767 \\
\hline Eureko Sigorta AŞ & Girdiler & İstihdam & 607 & 334 & -273 \\
\hline
\end{tabular}




Poliçe adet $\quad 1765004 \quad 971995 \quad-793009$

Tablo 7'ye göre en düşük etkinlik skoruna sahip olan sigorta şirketi Eureko Sigorta AŞ'dir. Eureko Sigorta AŞ 2018 yılı içinde 334 personel ile 971995 poliçe üretimi yapabilseydi, kullanılan girdi ve çıktı miktarları kapsamında tam etkinlik skoruna ulaşabilecekti. En düşük etkinlik düzeyinden tam etkinlik düzeyine doğru sıralama olarak bakıldığında diğer sigorta şirketleri sırasıyla Güneş Sigorta AŞ, Neova Sigorta AŞ, Doga Sigorta AŞ, Mapfre Sigorta AŞ, Sompo Sigorta AŞ, Anadolu Anonim Türk Sigorta Şirketi, Aksigorta AŞ, Axa Sigorta AŞ, Halk Sigorta AŞ'dir.

Örneklem olarak seçilen sigorta şirketlerinin 2019 yılına ait etkinlik skorları Tablo 8'de verilmiştir. 2019 yılı içinde tam etkinlik düzeyine ulaşan sigorta şirketleri Aksigorta AŞ, Ziraat Sigorta, AŞ. Bupa Acıbadem Sigorta AŞ olmuşlardır.

Tablo 8. 2019 yılı Sigorta Şirketlerine ait Gerçekleşen ve Olması Gereken Girdi Değerleri

\begin{tabular}{|c|c|c|c|c|c|}
\hline Sigorta Şirketleri-2019 & Değişkenler & Değişkenler & Gerçekleşen & Hedef & Fark \\
\hline \multirow{2}{*}{ Allianz Sigorta AŞ } & \multirow{2}{*}{ Girdiler } & İstihdam & 1592 & 1306 & -286 \\
\hline & & Poliçe adet & 3895777 & 3195196 & -700581 \\
\hline \multirow[t]{2}{*}{ Anadolu Anonim Türk Sigorta Şirketi } & \multirow{2}{*}{ Girdiler } & İstihdam & 1334 & 1141 & -193 \\
\hline & & Poliçe adet & 4897030 & 4189243 & -707787 \\
\hline \multirow[t]{2}{*}{ Aksigorta AŞ } & \multirow{2}{*}{ Girdiler } & İstihdam & 662 & - & - \\
\hline & & Poliçe adet & 4103720 & - & - \\
\hline \multirow{2}{*}{ Axa Sigorta AŞ } & \multirow{2}{*}{ Girdiler } & İstihdam & 698 & 629 & -69 \\
\hline & & Poliçe adet & 3900976 & 3515771 & -385205 \\
\hline \multirow[t]{2}{*}{ Sompo Sigorta AŞ } & \multirow{2}{*}{ Girdiler } & İstihdam & 647 & 516 & -131 \\
\hline & & Poliçe adet & 5088268 & 4054637 & -1033631 \\
\hline \multirow[t]{2}{*}{ HDI Sigorta AŞ } & \multirow{2}{*}{ Girdiler } & İstihdam & 644 & 472 & -172 \\
\hline & & Poliçe adet & 3095011 & 2266883 & -828128 \\
\hline \multirow[t]{3}{*}{ Mapfre Sigorta AŞ } & \multirow{3}{*}{ Girdiler } & İstihdam & 603 & 515 & -88 \\
\hline & & Poliçe adet & 1652369 & 1410855 & -241513 \\
\hline & & İstihdam & 172 & - & - \\
\hline \multirow[t]{2}{*}{ Ziraat Sigorta AŞ } & \multirow[t]{2}{*}{ Girdiler } & Poliçe adet & & & \\
\hline & & & 5549357 & - & - \\
\hline \multirow[t]{3}{*}{ Güneş Sigorta AŞ } & & İstihdam & 613 & 368 & -245 \\
\hline & Girdiler & Poliçe adet & 2843913 & 1705787 & -1137126 \\
\hline & \multirow{2}{*}{ Girdiler } & İstihdam & 257 & 247 & -10 \\
\hline Halk Sigorta AŞ & & Poliçe adet & 2902272 & 2785936 & -116336 \\
\hline \multirow[t]{2}{*}{ Neova Sigorta AŞ } & \multirow{2}{*}{ Girdiler } & İstihdam & 251 & 196 & -55 \\
\hline & & Poliçe adet & 2673358 & 2086019 & -587339 \\
\hline
\end{tabular}




\begin{tabular}{lccccc}
\hline Bupa Acıbadem Sigorta AŞ & Girdiler & İstihdam & 348 & - & - \\
& & Poliçe adet & 148190 & - & - \\
Doga Sigorta AŞ & Girdiler & İstihdam & 270 & 197 & -73 \\
& & Poliçe adet & 2448125 & 1784108 & -664016 \\
Eureko Sigorta AŞ & Girdiler & İstihdam & 667 & 274 & -393 \\
& & Poliçe adet & 1688786 & 693762 & -995024 \\
\hline
\end{tabular}

Yine Tablo 8'e göre tam etkinlik skoru olan 1'e en uzak olan sigorta şirketi Eureko Sigorta AŞ' dir. Buna göre 2019 yılında şirketin etkin olabilmesi için 274 personel ve 693762 poliçe adeti ile aynı çıktı düzeyine ulaşabilmesi mümkündü. 2019 yılında en düşük etkinlik düzeyinden tam etkinlik düzeyine doğru sıralama olarak bakıldığında diğer sigorta şirketleri sirasıyla Eureko Sigorta, Güneş Sigorta, Doğa Sigorta, HDI Sigorta, Neova Sigorta, Sompo Japan Sigorta, Allianz Sigorta, Maphre Sigorta, Anadolu Sigorta, Axa Sigorta, Halk Sigorta, AK Sigorta-Bupa Acıbadem Sigorta-Ziraat Sigorta olarak gitmektedir.

\section{Tartışma, Sonuç ve Öneriler}

Sigortacılık sektörü özellikle son dönemde finans dünyası içinde önemli bir gelişim ivmesi yakalamıştır. Ülkemiz açısından analizde kullanılan göstergelerde de görüldügü üzere sektörde büyüme noktasında önemli ilerlemeler kaydedilmiştir. Her ne kadar Türk finans sistemi içindeki oranı neredeyse yüzde 90 seviyesine ulaşan bankacılık sektörünün büyüklüğü ile kıyaslanamayacak seviyede de olsa sigortacılık sektörü önümüzdeki dönemde bu gelişimini daha da ileri seviyelere taşıyarak finans sektörü içinde kayda değer bir düzeye gelebilecek bir potansiyeli bünyesinde barındırmaktadır. Nitekim son dönemde sektörde karlılık ve aktif büyüklükleri her yıl bir önceki yıla göre önemli artışların söz konusu olması bu potansiyelin de en önemli göstergesidir.

Çalışmada veri zarflama analizi ile 2016-2019 yılları arasında sektörde prim üretimine göre üst sıralarda yer alan ve örneklem olarak seçilen sigorta şirketlerinin etkinlik analizi gerçekleştirilmiştir. Buna göre prim üretimine göre incelenen yıllarda sürekli 1.sırada yer alan Allianz Sigorta AŞ.'nin genel olarak etkinlik skoru maksimum ve maksimuma yakın seviyededir. Aynı şekilde toplam prim üretiminde ele alınan şirketler arasında son sırada yer alan Eureko Sigorta AŞ’nin de veri zarflama analizine göre skoru bir yıl hariç diğer yıllarda tam etkinlikten uzak düzeydedir. Ancak bununla birlikte Ziraat Sigorta toplam prim üretimine sektörde orta sıralardayken veri zarflama analizine göre her yıl tam etkinlik skoru olan 1'e ulaşmıştır. Bu noktada bu durum aynı zamanda analizde çıktı göstergesi olarak kullanılan net kar rakamının da yüksek olarak izlenmesine bağlanmaktadır. Bununla beraber etkinlik düzeyleri düşük olan sigorta şirketlerinin minimum girdi ile maksimum çıktıyı elde etme noktasında performans göstergelerini yeniden değerlendirmesi gerekmektedir. Her ne kadar teknolojinin istihdama etkisi negatif düzeyde olsa da daha çok sigortalıya ulaşma noktasında şubeleşme sayılarını arttırarak ölçek ekonomilerinden yararlanabilmeli, karlılıklarını arttıracak yenilikçi politikaları, yeni sigorta türlerini bulma noktasında çalışmalarını arttırmalıdırlar. Bu süreç hem sistemdeki sigortalanan değer sayısını arttıracak, 
hem sigortacılık sisteminin daha da büyümesine katkı sağlayarak doğrudan finans sektörünün ve ülke ekonomisinin büyümesine katkı sağlayacaktır.

Çalışmamız gerek sigortacılık alanındaki akademik yazına gerekse pratikte sigorta şirketleri ve paydaşlarına yol gösterici nitelikte olmakla beraber her çalışmada olduğu üzere çalışmamızın da bir takım kısıtları mevcuttur. Bu noktada veri zarflama analizi sadece örneklem olarak belirlenen girdi ve çıtı kalemlerine göre sonuçların yorumlanabilmesine imkan sunmaktadır. Çalışmada farklı girdi ve çıtı kalemleri ile farklı sonuçlar elde edilebilir. Ancak bu noktada çalışmamızda, sektörde sıklıkla performans göstergesi olarak değerlendirilen net kar/zarar, toplam prim üretimi, poliçe adeti gibi göstergeler üzerinden analizimin gerçekleştirilmesi nedeniyle, sektördeki prim üretimine göre ortaya çıkan sıralama ile etkinlik düzeyleri arasında genel olarak aynı yönde bir eğilim ortaya çıkarmıştır.

\section{Kaynakça}

Akgöbek, Ö., Nişanci, İ., Kaya, S. \& Tamer, E. (2015). Veri Zarflama Analizi Yaklaşımını Kullanarak Bir Eğitim Kurumunun Şubelerinin Performanslarını Ölçme. Sosyal Bilimler Araştırma Dergisi, 4(3), 43-54.

Akyüz, K. C., Çamur, G., \& Yıldırım, İ. (2015). Mobilya ve levha sektöründe veri zarflama analizi yardımıyla etkinlik ölçümü. Türkiye Ormancılık Dergisi, 16(1), 50-59.

Altan, M.S. (2010). Türk Sigortacllık Sektöründe Etkinlik: Veri Zarflama Analizi Yöntemi ile Bir Uygulama. Gazi Üniversitesi İktisadi ve İdari Bilimler Fakültesi Dergisi, 12(1), 1-20.

Aydın, Y. (2019). Türkiye'de hayat $\backslash$ emeklilik sigorta sektörünün finansal performans analizi. Finans Ekonomi ve Sosyal Araştırmalar Dergisi, 4(1), 107-118.

Ayhan, C., \& Özcan, A. (2018). Türkiye'de sigortacilık sektöründe etkinlik analizi (2010-2016). Journal of Social And Humanities Sciences Research (JSHSR), 5(16), 78-93.

Babacan, A., \& Özcan, S. (2009). Alanya Bölgesi Otellerinin Göreli Etkinliğinin Belirlenmesi: Bir Veri Zarflama Analizi Tekniği Uygulaması. Mustafa Kemal Üniversitesi Sosyal Bilimler Enstitüsü Dergisi, 6(12), 176-189.

Babatunde, J. H., \& Haron, R. (2015). Technical efficiency of Nigerian insurance companies: a data envelopment analysis and latent growth curve modelling approach. Int. J. Data Envelopment Analysis, 3(2), 659-677.

Bakhshoodeh, M. \& Kenneth, T. (2001). Input and Output Technical Efficiencies of Wheat Production in Kerman, Iran, Agricultural Economics, 24, 307-313.

Başkaya, Z. \& Akar, C. (2005). Sigorta şirketlerinin satış performanslarının veri zarflama analizi yöntemiyle belirlenmesi. Muğla Üniversitesi Sosyal Bilimler Enstitüsü Dergisi, (15), 3751.

Başkır, M. B. (2015). Sigorta piyasasında finansal performansın klasik ve bulanık öbekleme yöntemleri ile incelenmesi. Bankacılık ve Sigortacılık Araştırmaları Dergisi, 2(7), 19-33.

Benyoussef, S., \& Hemrit, W. (2019). Measuring the relative efficiency of insurance companies in Saudi Arabia: The case study of Takaful vs cooperative industries. Cogent Economics $\mathcal{E}$ Finance, 7(1), 1-20. 
Charnes A., Cooper, William W., \& Rhodes, E. (1978). "Measuring the Efficiency of Decision Making Units", European Journal of Operational Research, 2(6), 429-444.

Cooper, W. W., L. M. Seiford, \& J. Zhu (2004). Return to Scale in Data Envelopment Analysis, in Handbook on Data Envelopment Analysis (W. W. Cooper, L. M. Seifort ve J. Zhu), Kluwer Academic Publisher, New York, 2, 41-69.

Çağlar, A., \& Öztaş, G. Z. (2016). Veri zarflama analizi ve analitik hiyerarşi süreci ile sigorta şirketlerinin finansal oran analizi. Çankırı Karatekin Üniversitesi İktisadi ve İdari Bilimler Fakültesi Dergisi, 6(2), 221-248.

Çakmak, D., \& Baştürk, F. H. Türk Sigortacıllk Sektörünün 2007-2018 Yıllarına Ait Performansının Oran Analizi Yöntemi ile Ölçülmesi ve Sektörün Ekonomik Büyüme Üzerindeki Etkisi. Çanakkale Onsekiz Mart Üniversitesi Uluslararası Sosyal Bilimler Dergisi, $4(2), 235-264$.

Çatıkkaş, Ö. \& Duramaz, S. (2020). Küresel ve Ulusal Gelişmeler Kapsamında Sigortacılık Sektörüne Genel Bir Bakış, Küreselleşmenin Finansal Ve Reel Yaşama Yansımaları, Ed. Selim Duramaz, Beta Yayınları: İstanbul.

Çiftçi, H. (2004). Türk sigorta sektörünün sorunları; DEA analizi ile Türk sigorta şirketlerinin etkinlik düzeylerinin belirlenmesi. Çukurova Üniversitesi Sosyal Bilimler Enstitüsü Dergisi, 13(1), 121-149.

Dalkılıç, N. (2012). Türkiye'de hayat dışı sigortacılık sektöründe etkinlik analizi. Muhasebe ve Finansman Dergisi, (55), 71-90.

Dash, M., \& Muthyala, A. (2018). Cost efficiency of Indian life insurance service providers using data envelopment analysis. Asian Journal of Finance $\mathcal{E}$ Accounting, 10(1), 59-80.

Duramaz, S. (2018). “Ege Bölgesi’nde Yer Alan Yükseköğretim Kurumlarında Lisans Düzeyinde Eğitim Veren Bankacılık ve Finans Bölümlerinin Etkinliklerinin Veri Zarflama Analizi ile Ölçülmesi", 5th International Congress on Political, Economic and Social Studies-ICPESS, 26-29 Ekim, Niğde, Türkiye.

Herand, D. \& Öztunç, S. (2014). “Sigorta Sektöründe Müşteri İlişkileri Yönetimi’nin Uygulanması ve Yazılım Seçimi”, KSÜ İ̈BF Dergisi, 4(1), 187-198.

Kar, A., \& Şahin, B. (2018). Türkiye' de özel sigorta şirketlerinin verimliliğinin değerlendirmesi. The Journal of Academic Social Science Studies, 69, 349-364.

Kılınç, F.E. (2009). Türk Sigortacılık Sektörünün Veri Zarflama Analizi Yöntemi İle Etkinliğinin Araştırılması. Süleyman Demirel Üniversitesi SBE, Yayınlanmamış Yüksek Lisans Tezi, Isparta.

Kutlar, Aziz ve Kartal, Mahmut (2004), “Cumhuriyet Üniversitesinin Verimlilik Analizi: Fakülteler Düzeyinde Veri Zarflama Yöntemiyle Bir Uygulama", Kocaeli Üniversitesi Sosyal Bilimler Enstitüsü Dergisi, Cilt:8, No:2, s.49-79.

Özcan, H. (2019). Türk Sigortacılık Sistemindeki Banka Kaynaklı Prim Üretimine Banka Şube Sayılarının Etkisi Üzerine Bir Araştırma. Ufuk Üniversitesi Sosyal Bilimler Enstitüsü Dergisi, $8(15), 327-342$.

Özçelik, F., \& Öztürk, B. A. (2019). Girdi olarak maliyetlere yönelik veri zarflama analizi modelleri ile göreli etkinlik analizi. Işsletme Araştırmaları Dergisi, 11(2), 1011-1028. 
Özden, Ü. (2008). Veri zarflama analizi (VZA) ile Türkiye'deki vakıf üniversitelerinin etkinliğinin ölçülmesi. İstanbul Üniversitesi İşletme Fakültesi Dergisi, 37(2), 167-185.

Segovia-Gonzalez, M. M., Contreras, I., \& Mar-Molinero, C. (2009). A DEA analysis of risk, cost, and revenues in insurance. Journal of the Operational Research Society, 60(11), 1483-1494.

Sharew, A., \& Fentie, G. (2018). Data Envelopment Analysis on Efficiency of Insurance Companies in Ethiopia. American Scientific Research Journal for Engineering, Technology, and Sciences (ASRJETS), 48(1), 138-170.

Tarkoçin, C., \& Gençer, M. (2010). Farklı girdi ve çıktı yaklaşımlarının veri zarflama analizi etkinlik sonuçlarına etkisi ve Türk ticari bankaları uygulaması. Bankacılar Dergisi, 72, 19-32.

Tezergil, S. A. (2018). Veri zarflama analizi ile Türk sigorta sektörünün elementer branşlarda değerlendirilmesi. İşletme Araştırmaları Dergisi, 10(1), 342-357.

Türkiye Sigorta Birliği (2018). 2018 Sektör Raporu. İstanbul.

Türkiye Sigorta Birliği (2019). 2019 Sektör Raporu. İstanbul.

Türkiye Sigorta Birliği (2021). Mali Tablolar ve İstatistikler, https://www.tsb.org.tr/tr/istatistikler, (25.06.2021).

Yalçınkaya, H., \& Duramaz, S. (2021). Türk Bankacılık Sisteminde Kamusal Sermayeli Bankaların Karşılaştırmalı Etkinlik Analizi: 2008-2017 Dönemi Değerlendirmesi. Manisa Celal Bayar Üniversitesi Sosyal Bilimler Dergisi, 19(Armağan Sayıs1), 211-230.

Yıldırım, M., \& Altan, İ. (2019). Sigorta Sektörünün Finansal Performansının Entropi Ağırlıklandırmalı TOPSIS Yöntemiyle Analizi ve Değerlendirilmesi. Insan ve Toplum Bilimleri Araştırmaları Dergisi, 8 (1), 345-358.

Waghavkar, M. P., \& Sananse, S. L. (2018). Using data envelopment analysis to measure, relative efficiency of public and private life insurance companies in India. International Journal of Statistics and Applied Mathematics, 3(1), 173-17. 